\title{
EL ANÁLISIS DE LA COHERENCIA EN UN ARTÍCULO DE OPINIÓN: UNA PROPUESTA INTEGRADORA
}

\author{
Pilar López Mora/Livia C. García Aguiar \\ Universidad de Málaga/Universidad de Granada
}

\section{Introducción}

Nuestro objetivo es realizar una aportación al análisis de los procedimientos de coherencia, entendida esta como una característica del proceso de comunicación, tanto como una característica del texto ${ }^{1}$. La publicación motivada por el $25^{\circ}$. aniversario de la caída del Muro de Berlín del artículo firmado por Ramín Jahanbegloo «La pasión por la democracia» nos sirve de vehículo para poner en práctica una propuesta integradora en la que se tiene en cuenta el proceso de recepción además del logro de la coherencia en un texto argumentativo cuya temática central es la evolución de las democracias liberales desde el fin de la Guerra Fría y el cambio de actitud del ciudadano democrático.

\section{Marco teórico: propuestas de análisis de la coherencia discursiva}

La coherencia discursiva ha sido objeto de distintas disciplinas y distintos puntos de vista con objetivos muy diferentes. Desde las primeras propuestas

\footnotetext{
1 Véase E. Bernárdez, «El texto en el proceso comunicativo», Revista de Investigación
} Lingüística, 6 (2), 2003, págs. 7-28. 
de Hobbs 2 , Van Djik ${ }^{3}$, Beaugrande y Dressler ${ }^{4}$ y Mann y Thompson ${ }^{5}$, las abundantes teorías que tratan de propiciar una descripción de la coherencia apuntan a un limitado mas heterogéneo elenco de factores. A la luz de todos ellos, la coherencia no se explica sin tener en cuenta, además de lo semántico y retórico, lo pragmático y cognitivo.

Para nosotros, la coherencia no es tan solo una característica inherente al texto, es una propiedad del proceso comunicativo. Estamos de acuerdo con Bernárdez ${ }^{6}$ en que la coherencia se alcanza en virtud de una negociación entre emisor y receptor y que «es imposible hablar de coherencia sin pensar en la posible comprensión por un determinado receptor». Así, como explican Calsamiglia y Tusón?:

La coherencia es una noción más extensa e incluye las relaciones pragmáticas, además de las relaciones semánticas e intratextuales. Es un concepto que se refiere al significado del texto en su totalidad, abarcando tanto las relaciones de las palabras con el contexto como las relaciones entre las palabras en el interior del mismo texto. Alude a la estabilidad y consistencia temática subyacente, asociada a la macroestructura (contenido), a la superestructura (esquema de organización) del texto, a su anclaje enunciativo (protagonistas, tiempo y espacio) y a las inferencias que activan los hablantes para interpretarlo a partir de conocimientos previos.

Recientemente, han aparecido propuestas de análisis interesantes, como el modelo de los componentes paralelos de Redeker ${ }^{8}$, inspirado en el de Schiffrin', que trata la coherencia en tres dimensiones relacionadas: la estructura semántica, la estructura retórica y la estructura secuencial. O el que establece, tomando como punto de partida la teoría de la Gramática Discursivo-Funcional (GDF), Núria Alturo ${ }^{10}$, que distribuye las dimensiones que concurren en la obtención de la coherencia en torno a tres componentes: el contextual, el conceptual y el gramatical, el cual, a su vez, se realiza en dos niveles: el semántico y el pragmático.

2 J. R. Hobbs, «Coherence and Coreference», Cognitive Science, 3, 1979, págs. 67-90.

3 Véanse T. A. van Dijk, Text and Context, Longman, Londres, 1977; y T. A. van Dijk, Macrostructures, N. J. Erlbaum, Hillsdale, 1980.

${ }^{4}$ R. de Beaugrande y W. Dressler, Introduction to Text Linguistics, Longman, Londres, 1981.

${ }^{5}$ W. C. Mann y S. A. Thompson, «Rhetorical Structure Theory», Text, 8, 1988, págs. 243-228.

${ }^{6}$ Cf. E. Bernárdez, op. cit., pág. 14.

${ }^{7}$ H. Calsamiglia Blancafort y A. Tusón Valls, Las cosas del decir. Manual de análisis del discurso, Ariel, Barcelona, 1999, págs. 221-222.

${ }^{8}$ G. Redeker, «Coherence and Structure in Text and Discourse», en W. Black y H. Bunt (eds.), Abduction, Belief and Context in Dialogue. Studies in Computational Pragmatics, John Benjamins, Ámsterdam, 2000, págs. 233-263.

${ }^{9}$ D. Schiffrin, Discourse Markers, Cambridge University Press, 1987.

${ }_{10}$ «Coherencia discursiva: dimensiones contextual, conceptual y gramatical», Círculo de Lingüística Aplicada a la Comunicación, 41, 2010, págs. 3-30. 
En una línea que potencia el protagonismo del texto, trabaja el enfoque configuracional el método desarrollado por Garrido"11, que permite facilitar la detección de una jerarquía entre unidades temáticas y hace más visible su organización dentro de un texto. Su puesta en ejecución aclara la estructura del discurso en cuanto unidad semántica compleja así como la ordenación de los temas principales y secundarios que se abordan en el texto mediante enunciados relacionados entre sí por integración o agregación.

Notable es también el creciente interés, por parte de las teorías pragmáticas, en relacionar la coherencia con la comprensión o coincidencia entre lo que se trata de comunicar y lo que se interpreta ${ }^{12}$ o coherencia por interpretación, como se denomina en Vilarnovo' ${ }^{13}$. Se trata de estudios sobre la comprensión de los textos que parten de perspectivas psicológicas, cognitivistas y pragmáticas, en los que se incluye el análisis de los mecanismos cognitivos y procesos inferenciales en la captación de la coherencia desde la pragmática de la recepción ${ }^{14}$.

Por otra parte, sin apartarse de lo asumido por las teorías mencionadas, tendremos en cuenta especialmente que «la estructura del texto está ligada a otros fenómenos de acción social [...] en los que el texto se integra» ${ }^{15}$, de lo que se deriva que la detección de la coherencia tiene que ver con el reconocimiento de modelos convencionales en la producción textual ${ }^{16}$ (como los tipos de texto

11 J. Garrido, «Unidades intermedias en la construcción del discurso», Estudios de Lingüística del español, 35, 2014, págs. 97-115.

${ }^{12}$ Cf. W. Kintsch y T. A. van Dijk, «Toward a model of text comprehension and production», Psychological Review, 85 (5), 1978, págs. 363-394; y A. Duro, «La coherencia textual en los modelos para la comprensión de textos: Kintsch et alii vs. Sanford y Garrod», Cognitiva, 1992, 4 (2), págs. 227-244.

13 A. Vilarnovo, «Coherencia textual: ¿coherencia interna o coherencia externa?», ELUA, 6, 1990, págs. 229-239.

14 Véanse W. Kintsch y T. A. van Dijk, op. cit.; R. G. van de Velde, «Inferences and Coherence in Text Interpretation», en E. Sozered (ed.), Text connexity and text coherence. Aspects, methods and results, H. Buske, Hamburgo, 1985, págs. 261-298; R. G. van de Velde, «Man, Verbal Text, Inferencing and Coherence», en W. Heydrich et alii (eds.), Connexity and Coherence: Analysis of Text and Discourse, Walter de Gruyter, Berlín y Nueva York, 1989, págs. 174-217; D. Long et alii, «The Role of Inferencial Processing in Reading Ability», en B. K. Britton y A. C. Graesser (eds.), Models of Understanding Text, Psychology Press, Nueva York y Londres, 1996, págs. 189-214; G. Parodi, Relaciones entre lectura y escritura: una perspectiva cognitiva discursiva. Bases teóricas y antecedentes empíricos, Ediciones Universitarias de Valparaíso, 2003; o los estudios que con unos fines muy concretos, en el ámbito del español, parten del Análisis Crítico del Discurso (ACD), como el de D. Cassany, «Aproximaciones a la lectura crítica: teoría, ejemplos y reflexiones», Tarbiya, Revista de investigación e innovación educativa del Instituto Universitario de Ciencias de la Educación, 32, 2003, págs. 113-132.

15 J. Garrido, «Construcción del discurso en noticias de prensa», Revista Española de Lingüística, 37, 2007, págs. 139-168.

16 Esto se relaciona con la asimilación convencional de (proto)tipos (secuencias textuales socialmente determinadas; modos de organización del discurso; tradiciones discursivas) y con la importancia de la intertextualidad que, desde las teorías cognitivistas, serían esenciales en 
de Adam) ${ }^{17}$. Por ello, asumimos que no solo los estudios mencionados, que se suscriben a la teoría sobre el análisis de la coherencia, dan luz sobre ella: también nos serán de suma utilidad las teorías de la moderna retórica, que ayudan a concretar la pertenencia de un escrito a un género y a perfilar el tipo de receptor destinatario de ese texto ${ }^{18}$. Igualmente notaremos el paralelismo de estas últimas con las aportaciones de otras perspectivas, como son algunos desarrollos de las teorías de la argumentación ${ }^{19}$, que, a nuestro parecer, en la práctica, hacen posible una integración de las propuestas de ambos modelos.

\section{Metodología para el análisis de la coherencia}

En nuestra propuesta trataremos de analizar: A) la coherencia contextual y conceptual, en tanto el texto pertenece a una determinada tradición y cumple ciertas expectativas que afectan tanto al proceso de emisión como al de recepción y B) la configuración del escrito y la estructura semántica y retórica en tanto procedimientos que guían la interpretación del lector, así como la consecución de la coherencia desde la pragmática de la recepción.

En un primer análisis (que corresponderá a la coherencia contextual o conceptual) se tendrán en cuenta los aspectos relativos a la tipología y el género en el que el texto se inserta de los que se derivan ciertas expectativas del lector en cuanto a los esquemas contextuales impuestos por estos marcos. De igual modo, en este apartado trataremos brevemente de otros parámetros pragmáticos esenciales: emisor e intencionalidad y perfil del receptor.

la co-construcción del texto, en consonancia con lo expuesto por E. Bernárdez, op. cit. Véase también, en referencia al discurso retórico político, T. Albadalejo, «Rhetoric and Discourse Analysis», en I. Olza, O. Loureda y M. Casado-Velarde (eds.), Language Use in the Public Sphere: methodological perspectives and empirical applications, Peter Lagn, Berna, 2004, 19-53, págs. 52-53.

${ }_{17}$ J. M. Adam, Les textes: types et prototypes. Récit, description, argumentation, explication et dialogue, Nathan, París, 1992.

18 Véase T. Albaladejo, «Retórica, política y comunicación digital. La ampliación de la poliacroasis», en E. del Río, M. Carmen Ruiz de la Cierva y T. Albaladejo (eds.), Retórica y política. Los discursos de la construcción de la sociedad, Instituto de Estudios Riojanos, Logroño, 2012, págs. 49-66.

${ }^{19}$ Cf. F. H. Eemere y R. Grootendorst, Argumentación, comunicación y falacias. Una perspectiva pragmadialéctica, Ediciones Universidad Católica de Chile, Santiago de Chile, ${ }^{2} 2006$ (1. ed. en inglés en 1992); D. Walton y E. C. Krabbe, Commitment in Dialogue. Basic Concepts of Interpersonal Reasoning, University of New York Press, Albany, 1995; C. M. Santibáñez Yáñez, «La presunción como acto de habla en la argumentación», Revista de lingüística teórica y aplicada, 48 (1), 2010, págs. 133-152; y C. M. Santibáñez Yáñez, «Teoría de la argumentación como epistemología aplicada», Cinta de Moebio, 43, 2012, págs. 24-39. Para los estudios sobre la teoría de la argumentación, cf. C. Perelman y L. Olbrechts-Tyteca, Tratado de la argumentación. La nueva retórica, Gredos, Madrid, ${ }^{5} 1989$ (1. ed. en francés en 1958); S. E. Toulmin, The uses of Argument, C.U.P, Cambridge, 1958; J. C. Ascombre y O. Ducrot, La argumentación en la lengua, Gredos, Madrid, 1994 (1. ed. en francés publicada en 1983); y, más recientemente, C. Plantin, La argumentación, Ariel, Barcelona, 1995 (obra original en francés publicada en 1996). 
A continuación, para lo que Alturo ${ }^{20}$ denomina coherencia secuencial y Redeker ${ }^{21}$, retórica y gramatical, trataremos de propiciar un análisis de la coherencia interna que integre explicaciones procedentes del ámbito de la retórica y de la teoría de la argumentación, puesto que se trata de un texto cuyo objetivo es defender una tesis ante un «auditorio».

Finalmente, en el análisis de la coherencia desde la pragmática del receptor, creemos interesante desde un punto de vista tanto teórico como didáctico prestar atención a las cuestiones relacionadas con la coherencia interna y externa, esto es, si se consigue la comprensión por parte de los lectores de la globalidad del texto y, teniendo en cuenta que estamos ante un texto persuasivo, tratar de determinar cómo se soluciona la obtención de los objetivos pragmáticos del autor desde la perspectiva de la recepción.

\section{El objeto de estudio}

Nuestro objeto de estudio es el texto «La pasión por la democracia» firmado por el filósofo iraní Ramín Jahanbegloo ${ }^{22}$, traducción española de «Is there a Democratic Evil?» a cargo de Jesús Cuéllar, publicado en el diario El País el 18 de noviembre de 201423. Su publicación estaba motivada por el vigésimo quinto aniversario de la caída del Muro de Berlín, hecho a partir del cual se analiza críticamente la evolución de la democracia.

Como ya se ha mencionado, el texto objeto de estudio es una traducción del texto original inglés. Si bien no es nuestra intención hacer un estudio de lingüística contrastiva, existen algunos aspectos que serán de interés para la reflexión sobre el texto, su adaptación al español y su recepción por parte del público objetivo. Como apunta Hernández ${ }^{24}$, los traductores de artículos de opinión suelen, en general, respetar al máximo el estilo y contenido del original. Según esta misma autora, concretamente el diario El País solo suele

${ }^{20}$ N. Alturo, op. cit.

${ }^{21}$ G. Redeker, op. cit.

22 Jahanbegloo es colaborador habitual del diario El País desde 2004. El acceso a todos los artículos firmados por el autor está disponible en <http://elpais.com/autor/ramin jahanbegloo/a/> [Consulta: jul. 2015]. En su primera colaboración, los responsables del periódico introducen la información necesaria para que el lector sepa que se encuentra ante una autoridad cuya opinión ha de ser tenida en cuenta: «Ramin Jahanbegloo, filósofo iraní, estudió en la Sorbona y en Harvard y enseña en el Cultural Reserch Bureau de Teherán. Es autor, entre otros, de Diálogo con George Steiner y de Diálogo con Isaiah Berlin». En los últimos artículos, la información sobre el autor se reduce a lo siguiente: «Ramin Jahanbegloo, filósofo iraní, es catedrático de Ciencias Políticas en la Universidad de Toronto».

23 Disponible en <http://elpais.com/elpais/2014/10/09/opinion/1412869566_881284.html> [Consulta: julio de 2014].

${ }^{24}$ M. J. Hernández Guerrero, «Los artículos de opinión traducidos en la prensa escrita: el trasvase cultural de la opinión», en M. J. Hernández Guerrero y S. Peña Martín (eds.), La traducción, factor de cambio, Peter Lang, Berna, 2008, págs. 93-114. 
variar el título y algunas características relativas a la adaptación al formato del periódico 25 .

Esos son, en nuestro caso, los cambios entre el texto original y el texto meta más notables: el título y la integración del destacado. Desde el punto de vista de la interpretación global del mensaje es muy importante la primera diferencia, ya que la del título constituye una modificación que conduce las expectativas previas a la lectura bien hacia el «mal democrático» (democratic evil), bien hacia la actitud recomendable (la pasión por la democracia).

En otros casos, de modo no intencional, la traducción afecta a la coherencia de manera que podría limitar la interpretación por parte de los lectores españoles. De hecho, tras la lectura de este texto por parte de nuestros alumnos de la asignatura «Expresión oral y escrita del español» del Máster de Gestión de Patrimonio Literario y Lingüístico del español de la Universidad de Málaga ${ }^{26}$, la conclusión fue (en un $80 \%$ ) que en ocasiones el texto no cumplía los requisitos de coherencia textual, concretamente en el siguiente fragmento:

Desde 1989 y la caída del Muro de Berlín la democracia liberal se ha impuesto a los demás sistemas de gobierno convencionales, pero, en todo el mundo, su ascendiente político no siempre ha ido acompañado del que conlleva la pasión democrática.

Comparémoslo con el original y notemos que la traducción de la voz ascendency 'influencia' se ha hecho sin tener en cuenta al lector español:

Since 1989 and the fall of the Berlin Wall liberal democracy has triumphed against all standard systems of governance, but liberal democracy's political ascendency around the world has not always been accompanied with the ascendency of democratic passion.

Si consideramos las posibles traducciones de esa palabra, concluiremos, dando la razón a nuestros alumnos, que la voz ascendiente en español no da claridad al párrafo y más bien oscurece el mensaje original del autor.

\section{El texto en sus dimensiones contextual y conceptual: coordenadas tipo- lógicas, sociológicas y culturales}

\subsection{Las coordenadas tipológicas del texto}

El mero hecho de estar producido dentro de unas coordenadas tipológicas (el género periodístico de opinión) hace que la detección de la coherencia por

${ }^{25}$ M. J. Hernández Guerrero, loc. cit., pág. 96.

${ }^{26}$ Durante el curso 2014/2015, pusimos en práctica una breve cala empírica en las clases que impartimos en el Máster de Gestión de Patrimonio Literario y Lingüístico del español de la Universidad de Málaga, para la que los alumnos de la mencionada asignatura realizaron un comentario crítico del texto a partir del cual surgió, entre otras, esta observación. 
parte del receptor dependa del cumplimiento de una serie de convenciones, es decir, el receptor tiene unas expectativas acerca de la actividad del emisor que no tiene que ver tanto con la «acción puramente intencional y libre» sino más bien con el habitus ${ }^{27}$. De este modo, la coherencia externa (pragmática o interpersonal) condiciona la coherencia interna. Y la consecución de la coherencia, así como su detección, tendrán relación con factores pragmáticos que actúan jerárquicamente en las decisiones del emisor de un texto en su formulación y conceptualización (en términos de la GFD) ${ }^{28}$, así como en la interpretación por parte del receptor.

Por otra parte, el artículo o artículo firmado es un subgénero periodístico que parte de una noticia de actualidad ${ }^{29}$, en este caso, el aniversario de la caída del Muro de Berlín, y en el que prima un objetivo definitorio: la formación de opinión en el público receptor: «El articulista intenta convencer al lector con unos argumentos para que adopte una determinada posición $»^{30}$.

En ese contexto, el receptor sabe que el emisor trata de expresar una opinión y justificar una conclusión, por lo que es más que probable que use para la formulación de sus ideas un modelo discursivo persuasivo. Por ello, desde la perspectiva de la recepción, el lector de un artículo de opinión espera encontrar un texto persuasivo, quizás reticente ante la presuposición de que el fin de todo texto de este tipo es convencerle de un punto de vista, en este caso, la defensa de la democracia en un contexto social, geográfico e histórico concreto.

Por otra parte, una tipificación adecuada al artículo de opinión que nos ocupa es la propiciada por Albadalejo ${ }^{31}$, en el marco de los estudios de la Retórica, que nos habla del «texto político periodístico». La prensa (y aún más la digital) es un medio de transmisión excepcional, un foro que el texto político aprovecha de muy diversos modos, pero sobre todo y más legítimamente en el espacio denominado de «opinión». Según Albadalejo ${ }^{32}$, textos políticos serían «tanto los discursos electorales como los discursos parlamentarios [...] pero también todos aquellos textos en los que se expone teoría política o en los que se mantienen determinadas posiciones políticas» $\mathrm{y}$, si bien no es el objetivo

${ }^{27}$ Cf. E. Bernárdez, op. cit., pág. 20.

28 Véase K. Hengeveld y J. L. Mackenzi, «La Gramática Discursivo-Funcional», Moenia, 17, 2011, págs. 5-45 (trad. española de D. García Velasco).

${ }^{29}$ P. Moreno Espinosa, «Géneros para la persuasión en prensa: los editoriales del diario El País», Ámbitos: Revista internacional de comunicación, 9-10, 2003, 225-238, pág. 226.

${ }^{30} \mathrm{R}$. Yanes Mesa, «El artículo, un género entre la opinión y la actualidad», Revista Latina de Comunicación Social, 58, 2004, pág. 8. Disponible en: <http://www.ull.es/publicaciones/ latina/20041858yanes.htm> [Consulta: julio de 2015].

31 T. Albaladejo, «El texto político de estructura periodística: la configuración retórica de su comunicación», en J. Garrido (ed.), La lengua y los medios de comunicación, I, Universidad Complutense, Madrid, 1999, págs. 390-396, apud T. Albaladejo, «El texto político de escritura periodística: la configuración retórica de su comunicación», Círculo de Lingüística Aplicada a la Comunicación, 1, 2000, págs. 3-12. Disponible en: <www.ucm.es/info/circulo/no1/albalade.pdf. $>$ [Consulta: julio de 2015].

${ }^{32}$ T. Albaladejo, loc. cit., pág. 4. 
del escritor aquí una persuasión de índole partidista, el artículo es evidentemente una llamada a la acción democrática, la apelación a la participación política. El trabajo de Albadalejo ${ }^{33}$ ayuda a perfilar la pertenencia de este texto a un género de escrito político principalmente deliberativo. Notamos el paralelismo de esta con las clasificaciones de otras perspectivas como la ofrecida por Walton ${ }^{34}$, que partiendo del modelo de Walton y Krabbe ${ }^{35}$ propone una descripción del discurso deliberativo que sería el que comienza con un dilema y acaba con una propuesta de acción («course of action») ${ }^{36}$.

\subsection{Las coordenadas socioculturales}

En este punto, cabría preguntarse quiénes son los destinatarios de este texto. La respuesta no es fácil: un texto periodístico va dirigido al público lato sensu $\mathrm{y}$, por tanto, el receptor potencial es el auditorio más amplio que podamos imaginar. No obstante, contamos con datos sobre el perfil sociológico del receptor: un lector del diario donde se publica el artículo «La pasión por la democracia». Así, según la lista de las noticias más vistas de El País, el lector habitual es un individuo «interesado por la cultura, la política y la economía», «mayoritariamente urbano, familiarizado con las nuevas tecnologías y con amplios intereses en el ámbito de la información», además, «tiene un grado de formación elevado» (El País, 12/03/2012) ${ }^{37}$.

En el marco de los estudios de Retórica, el tipo de receptor al que va dirigido un texto se define no por su perfil sociológico sino por su capacidad en la toma de decisiones; así, como estableció Aristóteles, el receptor puede ser juez de cosas pasadas, árbitro de decisiones futuras o espectador: la diferencia esencial es que los dos primeros tienen capacidad de decidir y actuar, en el

${ }_{33}$ T. Albaladejo, «Retórica, política y comunicación digital».

${ }^{34}$ D. Walton, Media Argumentation. Dialectic, Persuasion and Rhetoric, Cambridge University Press, 2007.

${ }^{35}$ Cf. D. Walton y E. C. Krabbe, loc. cit.

${ }^{36}$ Evidentemente, el carácter del texto escrito ante el que nos encontramos reduce las características formales del modelo de Walton y carece de una de las pruebas más interesantes que la dialéctica ofrece: el feedback de un opositor real. Sin embargo, de acuerdo con E. Bernárdez, op. cit., estimamos que todo texto tiene una base conversacional, esto es, se construye sobre las mismas bases que una conversación, pues el emisor siempre tiene presente al receptor en su producción.

${ }^{37}$ Por otra parte, el alcance del texto desde un punto cuantitativo, según el último informe publicado por la Encuesta General de Medios para los meses de octubre y noviembre de 2014, confirma que el diario El País es el periódico generalista no deportivo más leído de España (Encuesta General de Medios, 3. ola 2014, octubre/noviembre, pág. 38. Disponible en $<\mathrm{http}$ // www.prisabs.com/pbs/egm/completo.pdf> [Consulta: enero de 2015]. En cuanto a su versión gratuita en línea, la misma fuente apunta, al referirse a los hábitos de lectura de noticias de los internautas españoles, que www.elpais.com se halla en el tercer lugar de visitas, tras You Tube y Marca (loc. cit., pág. 59). 
caso del segundo, además, sobre asuntos que aún no están resueltos ${ }^{38}$. Por tanto, estamos aquí ante el segundo caso de receptor: el que tiene facultad para decidir.

En el texto objeto de nuestro interés se habla de la «democracia»: un concepto lingüístico que corresponde a una realidad social y filosófica cuya evolución no lo hace inequívoco; siendo a veces que en el texto se habla de las democracias liberales, y que el lector sabe que es común utilizar el término democracia como sinónimo de democracia liberal, que en muchos casos se identifica de modo peyorativo con la «regla de la mayoría» ${ }^{39}$ y con lo que el propio autor denomina «mal democrático», o bien con liberalismo económico con todos los matices de simpatía y antipatía que ello pueda despertar en el posible lector ${ }^{40}$. Esta premisa conlleva la necesidad de superar un conflicto derivado de la consideración de la democracia como sistema político fracasado. Este desencuentro necesita para ser superado, como se asume en las teorías pragmadialécticas, de una argumentación, entendida como intento verbal razonado de superar ese conflicto ${ }^{41}$. Por este motivo, para determinar la consecución de los objetivos pragmáticos del autor desde la perspectiva de la recepción puede ser de interés asociar nuestros estudios con los parámetros de la lógica informal y de la plausibilidad.

\section{La coherencia interna a la luz de la intencionalidad}

\subsection{La configuración del escrito y la coherencia semántica y retórica}

En lo relativo al contenido, su estructura y su modo de organización, el texto se formula de modo inductivo, a partir de la enunciación de un dilema («El siglo XXI constituye una encrucijada») que sirve para dar paso a una serie de segmentos o secuencias textuales consistentes en una deliberación crítica sobre la democracia. El texto se organiza en nueve párrafos que, desde un punto de vista superestructural, tienen un desarrollo desigual. Esencialmente, en su organización interna detectamos que desde el inicio hasta la mitad del

${ }^{38}$ Véanse T. Albaladejo, «El texto político de estructura periodística», y M. del C. Ruiz de la Cierva, «Los géneros retóricos desde sus orígenes hasta la actualidad», Rhêtorikê: revista digital de retórica, 0,2008 , págs. 1-40.

${ }^{39}$ D. Beethan y K. Boyle, Cuestiones sobre la democracia: conceptos, elementos y principios básicos, Libros de la Catarata, Madrid, 1996.

${ }^{40} \mathrm{E}$. Langer, «El fin de la democracia liberal: La desigualdad en las sociedades capitalistas post-democráticas», conferencia presentada en el II Foro de la Asociación Internacional de Sociología dedicada a "La justicia social y la democratización», Buenos Aires, agosto de 2012. Disponible en $<\mathrm{http}$ ://www.tni.org/es/paper/el-fin-de-la-democracia-liberal $>$ [Consulta: diciembre de 2014].

${ }^{41}$ Véanse F. H. Eemere y R. Grootendorst, op. cit.; y S. Greco Morasso, «Argomentare per superare il conflitto: l'argomentazione nella mediazione», en F. Paglieri (ed.), Argomentazione, processi cognitivi e nuove tecnologie, Special issue of Sistemi Intelligenti, 3 (2), 2012, páginas 513-533 
párrafo cuarto, los subtemas y el modo de organización del discurso tienen un carácter que propicia su interpretación como un bloque temático e intencional que difiere de lo que viene a continuación de la secuencia encabezada por «con todo»:

Con todo, la experiencia nos demuestra que es muy difícil encasillarla en un único significado, ya que significa cosas diversas para distintas personas en diferentes contextos.

El texto en su primera parte muestra una forma verbal marcadamente dialógica y concesiva, en un reconocimiento de los defectos del sistema político que se quiere defender. Los conectores más utilizados son los contrargumentativos (sin embargo, pero, no obstante) encabezando las proposiciones que vehiculan los argumentos nucleares. El uso del léxico propicia mediante la antítesis el reflejo de un contraste desde el que el lector puede asumir sin dificultad una evolución negativa de la democracia.

Las crisis y las crueldades registradas en Bosnia, Ruanda, Darfur, Afganistán e Irak han llevado a muchos a concluir que el nuevo orden mundial es más bien un nuevo desorden mundial.

Para muchos estaba claro que la Guerra Fría era la confrontación entre el autoritarismo soviético y la democracia. Pero al caer el Muro de Berlín, [...]. Todas las formas de disidencia que la democracia liberal albergaba o aquellas que se le oponían se convirtieron en objeto de censura y sospecha.

Esta proliferación de voces como disidencia, censura, sospecha, apatía... se suma al uso de la negación (no todo parece estar bien en la democracia; su ascendiente político no siempre ha ido acompañado del que conlleva la pasión democrática; el individuo demócrata ya no es un animal caracterizado por la pasión política; en los sistemas democráticos actuales ya no hay lugar para el debate político) y la concesividad para corresponder a un contenido que comporta una visión pesimista del tema central (la democracia), al tiempo que una continua contraposición del pasado y el presente:

Desde 1989 y la caída del Muro de Berlín la democracia liberal se ha impuesto a los demás sistemas de gobierno convencionales, pero, en todo el mundo, su ascendiente político no siempre ha ido acompañado del que conlleva la pasión democrática. El individuo demócrata ya no es un animal caracterizado por la pasión política. Parece que en los sistemas democráticos actuales ya no hay lugar para el debate político.

Las estructuras van a fomentar esta representación semántica que conduce a una interpretación concreta mediante procedimientos textuales ${ }^{42}$ que facilitan

\footnotetext{
${ }^{42}$ T. Albaladejo, «Retórica, política y comunicación digital».
} 
la interpretación de relaciones jerárquicas en la sintaxis e inciden en el reconocimiento de coherencia por parte del receptor. Esto se hace evidente en la segunda mitad del texto ${ }^{43}$, es entonces cuando percibimos una transición entre una revisión negativa de la democracia y la reflexión que posibilita reconciliarse con ese concepto:

Con todo, la experiencia nos demuestra que es muy difícil encasillarla en un único significado, ya que significa cosas diversas para distintas personas en diferentes contextos. Esto es lo que explica que no se consiga «extender», por no hablar de «exportar», la democracia de una cultura o sociedad a otra. La razón es sencilla: el fomento de la democracia no puede funcionar en ausencia de una cultura democrática y organizar elecciones es sólo el punto de partida de la vida democrática de un país.

Así, el recurso a operadores de refuerzo argumentativo ${ }^{44}$ como «de hecho» o «en realidad» (párrafo 5) permite guiar las implicaturas ${ }^{45}$ y obliga a una interpretación de lo dicho que induce a revisar el concepto de democracia desde una perspectiva diferente:

De hecho, la auténtica prueba de la democracia no radica precisamente en dar poder a una mayoría victoriosa, otorgando la mayor libertad al mayor número posible de personas, sino que en realidad se basa en una nueva actitud, una nueva forma de abordar el problema del poder y la violencia.

En esta segunda mitad, y tras la asociación en el entretejido textual de la práctica democrática con la ausencia de violencia «y un conjunto de garantías institucionales opuestas a la avasalladora lógica del Estado», se previene del mayor peligro que entraña la democracia cuando el ciudadano se ha desentendido de ella, id est, la corrupción, definida como «mal democrático»:

(1) Antes de responder a esta pregunta creo que podemos apuntar al problema de la corrupción en las democracias y calificarlo de mal democrático. (2) Ese mal constituye un problema porque surge en el seno de las democracias y atañe a algo concreto: la legitimidad de la violencia. (3) $\mathrm{Al}$ reconocer que esta resulta problemática para la democracia se recalca la condición del homo democraticus y la posibilidad de que las democracias degeneren en violencia.

${ }^{43}$ Es interesante notar que esta segunda parte coincide en el texto original con un nuevo párrafo.

${ }^{44}$ V. M. A. Martín Zorraquino y J. Portolés, «Los marcadores del discurso», en I. Bosque y V. Demonte (dirs.), Gramática descriptiva de la lengua española, III, Espasa Calpe, Madrid, 1999, págs. 4051-4214.

${ }^{45}$ M. C. Errázuriz Cruz, «El desarrollo de la escritura argumentativa académica: los marcadores discursivos», Onomázein, 2014, 217-236, pág. 220. 
Desde el punto de vista configuracional ${ }^{46}$, el segmento (1) abre camino a la ampliación del tema mediante una serie de enunciados coordinados (1-3). Existe una conexión jerárquica que conduce a establecer la configuración que se interpretaría como coherente o, dicho de otro modo, instruye al receptor para otorgar coherencia al texto y detectar que la información relevante se expresa en (2) y (3). Desde un punto de vista argumentativo, este es sin duda un argumento fuerte, pues evoca una imagen indeseada y pone de relieve lo que está en juego: el riesgo de que «las democracias degeneren en violencia», dado el carácter paradójico de la propia democracia:

(4) En consecuencia, para ir más allá de la violencia democrática habrá que reconocer primero el carácter paradójico de la propia democracia, que es el proceso por el cual se domeña la violencia, pero los Estados y las sociedades democráticos también la generan.

Esa paradoja en (4) es útil a los fines pragmáticos del autor desde el punto de vista de la recepción, pues la violencia es una razón de peso (un argumento fuerte) para generar una reacción intelectual de rechazo que da pie a introducir, finalmente, la apelación a la responsabilidad del ciudadano. Por ello, consideramos que este fragmento (párrafo 6) es el central desde un punto de vista retórico, semántico y temático. A partir de ahí, la progresión informativa se hace proporcionando argumentos que tratan de reconducir la actitud del lector en tanto homo democraticus, entre los que no falta el recurso a la cita de autoridad:

Václav Havel nos recuerda que la «democracia es un sistema basado en la confianza en el sentido de la responsabilidad del ser humano, que debería despertar y cultivar».

La inclusión del lector en el espacio textual se hace clara mediante preguntas retóricas ${ }^{47}$, marcadores concesivos y una configuración de las secuencias textuales, que parte de formulaciones negativas para introducir los componentes nucleares frente a los subordinados ${ }^{48}$.

46 J. Garrido, «Unidades intermedias en la construcción del discurso».

${ }^{47}$ Como afirma D. Dumitrescu, «Función pragma-discursiva de la interrogación ecoica usada como respuesta en español», en H. Haverkate, K. Hengeveld y G. Mulder (eds.), Aproximaciones pragmalingüiśticas al español, Rodopi (Diálogos Hispánicos, no. 12), Ámsterdam, 1993, 51-86, pág. 68, «... una pregunta retórica, en virtud de su fuerza ilocutiva asertiva, puede ser usada por el hablante como respuesta a una pregunta previa "verdadera" del interlocutor» (esto es, le da voz en el texto) y, además, «... el hablante que escoge esta alternativa [retórica] quiere, a la vez, atacar la validez misma de la pregunta». Así, el uso de estas preguntas, analizables como concesiones a los prejuicios, buscarían paulatinamente reconducir la actitud del lector.

48 J. Garrido, «Unidades intermedias en la construcción del discurso». 
Ante esos problemas y los múltiples indicios de que no todo parece estar bien en la democracia, nos preguntamos: ¿qué queda de la democracia como discurso y como institución?

¿Pero cómo podemos reavivar ahora, en unos ciudadanos malcriados por el bienestar o resentidos por su exclusión del mismo, la pasión por la democracia?

[...] ¿cómo podrían los ciudadanos pensar en la política hoy en día y luchar por la aparición de nuevas perspectivas de vida democrática?

El escritor prevé que la aceptación de sus conclusiones va a depender de la disposición del receptor de aceptar y asumir la validez argumentativa de las aserciones como realidades ${ }^{49}$.

De este modo, lo que se abre con un dilema (la «encrucijada» en que el hombre del siglo XXI se halla frente a los problemas derivados de la evolución de la democracia), se resuelve con una propuesta de acción: «un esfuerzo moral» que es la clave para la resolución del conflicto desarrollado a lo largo del texto. Para ello, el autor, si bien recurre a valores subjetivos y emocionales, usa en su expresión un modo asertivo y conclusivo que constituye el cierre de la discusión:

Este sentido de la responsabilidad común es la clave de nuestra identidad como seres demócratas, porque, en nombre de la dignidad y la vulnerabilidad que los seres humanos compartimos, se alza como reacción ante lo intolerable. Es un esfuerzo moral que nos revela la complejidad, la espontaneidad y la heterogeneidad de la democracia.

\subsection{La coherencia de interpretación desde la argumentación}

Como toda argumentación orientada hacia un auditorio ${ }^{50}$, la función del texto es 1) tratar de guiar al lector en cierto proceso de aceptación de una tesis (la necesidad de acción, la recuperación de una actitud participativa) y 2) tratar de explicar y justificar los criterios que hacen esa tesis aceptable para el auditorio (la necesidad de salvaguardar la democracia; la responsabilidad moral del ciudadano democrático).

Una evaluación crítica desde la lógica informal ${ }^{51}$ establece la relación entre las premisas, la conclusión y el receptor interponiendo tres criterios: la relevancia de las premisas y la conclusión, la suficiencia de los argumentos para sustentar la tesis y, por último, la aceptabilidad de la argumentación a juicio del receptor en términos cercanos a la plausibilidad ${ }^{52}$.

${ }^{49}$ Cf. C. M. Santibáñez Yáñez, «La presunción como acto de habla»; y G. Fernández Smith, «Contexto pragmático y receptor: La aceptabilidad como norma textual», Revista de Investigación Lingüistica, 16, 2013, págs. 61-88.

${ }^{50}$ C. M. Santibáñez Yáñez, «Teoría de la argumentación».

${ }^{51}$ C. M. Santibáñez Yáñez, loc. cit., págs. 35-36.

${ }^{52} \mathrm{Cf}$. V. Le Floch, «Plausibility judgment of causally related social events: Impact of conceptual coherence and word-coherence», Journal of Pragmatics, 40 (7), 2008, págs. 1202-1215. 
La conclusión a la que llega el autor es que ya que 1) la democracia depende del ciudadano demócrata y 2) garantiza el autogobierno y da el poder a la sociedad, 3) el insinuado fracaso de la democracia en (2) es, en última instancia, responsabilidad del ciudadano. Teniendo en cuenta la coherencia lógica de esta conclusión debemos reconocer su plausibilidad, basada en la aceptabilidad de la primera premisa. Esta conclusión es crucial para el avance de los argumentos pues es el punto de arranque del fin último del texto (la apelación o llamada a la acción del lector como ciudadano demócrata).

\section{Conclusiones}

En lo anterior se ha puesto en práctica una metodología que tiene en cuenta el carácter tipológico del texto para analizar la coherencia (interna y externa) a la luz de su modo de organización discursiva en tanto texto argumentativo. Desde esta perspectiva, las estrategias retóricas y semánticas utilizadas se muestran más claramente relacionadas con los fines pragmáticos de un texto político persuasivo. La intención comunicativa persuasiva se ajusta perfectamente al tipo de texto elegido: un texto periodístico de opinión del género político-deliberativo cuyo emisor pretende convencer a un auditorio capaz de decidir respecto del asunto que se trata; en relación con esto, también conviene al tipo textual la elección del punto de partida temático que es una noticia de actualidad: el aniversario de un acontecimiento histórico de relevancia (la caída del Muro de Berlín).

La elección del título en la versión española, en contraste con el original, delata la idea global que se pretende comunicar: debemos recuperar la pasión por la democracia, apartando de la mente del lector las evocaciones negativas que el título original pudiera transmitir.

El carácter con el que se van introduciendo las ideas, sobre todo en la primera parte del texto, es polémico y conflictivo, ya que las informaciones locales ponen de relieve los defectos de las actuales democracias liberales, en una acumulación de reflexiones, tras las que Jahanbegloo (ya en la segunda mitad del escrito) aporta una serie de argumentos en favor de la idea de que la democracia es la salvaguarda de la paz y que representa un sistema de valores que merecen un mayor esfuerzo por parte del ciudadano. Esta estrategia, concesiva y marcadamente dialógica, cumple con los objetivos fundamentales de un texto argumentativo (cuyo fin es la superación de un conflicto) proporcionando una apariencia polifónica, dando «voz» a los lectores, abriendo un «debate».

El texto concluye con una apelación a la responsabilidad del ciudadano demócrata, en nombre de valores morales esenciales con los que debe comprometerse. En este punto, el texto logrará su objetivo pragmático y será coherente con sus propósitos si resulta convincente a los lectores. En este sentido, un factor para la admisión de los argumentos es una cuestión de confianza que el lector, en este caso, otorga al autor del texto principalmente por cuestiones 
de prestigio intelectual: presumiblemente, el filósofo y catedrático de ciencias políticas posee los conocimientos sobre la materia de la que habla. Es aquí donde el análisis de la coherencia discursiva delata más su dependencia de las expectativas del lector. Por otra parte, como hemos apuntado, otra condición que hace que una argumentación tenga una buena recepción es la plausibilidad del razonamiento, lo que tiene que ver y mucho con la manera en que esos argumentos se exponen: por un lado, el modo concesivo, la apertura al diálogo, la valoración de pros y contras, incluyen al lector en el proceso textual; de otro lado, herramientas retóricas como la cita de autoridades irreprochables o la enunciación de la conclusión no como una opinión sino como una certeza son muestras verbales de seguridad que aumentan la confianza de los lectores en la autoridad del escritor.

La propuesta metodológica desarrollada ha demostrado su utilidad en el análisis de los procedimientos de coherencia en un texto argumentativo. Por una parte, la atención a las expectativas de los lectores puestas en relación con la tipología de los escritos es una base imprescindible para explicar las estrategias retóricas y semánticas que el emisor pone en juego al redactar un texto sin perder de vista la mirada del otro; de otro lado, es de suma importancia un análisis de las secuencias discursivas que busque relacionar lo semántico y temático con una estructura gramatical intencional en la que las decisiones del escritor serán esenciales para lograr un texto no solo bien cohesionado y redactado de modo satisfactorio, sino que cumpla con los fines pragmáticos con los que se ha comprometido; en nuestro caso, la persuasión o, al menos, la consecución de asentimiento con una determinada actitud política por parte de un auditorio. Finalmente, creemos que este tipo de análisis resulta de suma utilidad e interés didáctico para lograr una lectura profunda y completa que permita la reflexión metalingüística desde una visión de la coherencia como una propiedad comunicativa global. 
